\title{
KONDISI KETENAGAKERJAAN DI JAWA BARAT DAN MEA
}

\author{
Oleh: \\ Nunung Nurwati
}

\begin{abstract}
ABSTRAK
Tulisan ini menyajikan kondisi ketenagakerjaan di Jawa Barat tahun 2013-2015, dengan menggunakan data utama hasil Sakernas 2013-2015. Beberapa temuan adalah sebagai berikut; tenaga kerja yang bekerja mayoritas berpendidikan SD dan SMP, sebagian besar dari mereka terserap di sektor informal.Begitu pula dengan penganggur sebagian besar berpendidikan SD dan SMP. Dengan kondisi tenaga kerja seperti itu, akan sulit bersaing dipasaran bebas. Munculnya pengangguran dikarenakan tidak tersedia kesempatan kerja, pertumbuhan angkatan kerja yang tinggi tidak dibarengi dengan pertumbuhan kesempatan kerja.

Dampak diberlakukannya MEA, memberi kesempatan kepada para tenaga kerja untuk bekerja di negara manapun, sebaliknya tenaga kerja yang berasal dari Jawab Barat memiliki kesempatan untuk bekerja di luar negri. MEA memiliki dampak positif bagi ketenaga kerja di Jawa Barat yaitu sektor pariwisata dapat berkembang sehingga dapat menyediakan peluang kerja bagi gtenaga kerja lokal,akan kebanjiran barang-barang atau produk luar dengan harga yang lebih murah daripada produk lokal. Dampak negatif seperti adanya barang-barang selundupan, pendatang gelap.Untuk menghadapi MEA Jawa Barat berupaya untuk fokus dalam meningkatakna kualitas SDM
\end{abstract}

\section{Kata kunci: ketenagakerjaan, pendidikan, pengangguran, informal}

\section{PENDAHULUAN}

Sejak Desember 2015 telah diberlakukan Pasar Asean, yang digagas dan dibentuk oleh negara-negara Asean dan disebut Masyarakat Ekonomi ASEAN (MEA). MEA merupakan bentuk realisasi dari tujuan akhir integrasi ekonomi di kawasan Asia Tenggara. Dengan terintegrasinya pasar Asean menjadi satu, maka akses yang lebih luas dan lebih mudah untuk bekeja di Negaranegara ASEAN, pekerja terdidik dan tersertefikasi dari Indonesia bebas untuk memilih bekerja di Negara anggota asean, begitupun sebaliknya

Dari aspek ketenagakerjaan, terdapat kesempatan yang sangat besar bagi para pencari kerja karena dapat banyak tersedia lapangan kerja dengan berbagai kebutuhan akan keahlian yang beraneka ragam. Selain itu, akses untuk pergi keluar negeri dalam rangka mencari pekerjaan menjadi lebih mudah bahkan bisa jadi tanpa ada hambatan tertentu. MEA juga menjadi kesempatan yang bagus bagi para wirausahawan untuk mencari pekerja terbaik sesuai dengan kriteria yang diinginkan. Namun demikian, hal ini dapat menimbulkan risiko ketenagakarjaan bagi Indonesia. Dilihat dari sisi pendidikan dan produktivitas Indonesia masih kalah bersaing dengan tenaga kerja yang berasal dari Malaysia, Singapura, dan Thailand serta fondasi industri yang bagi Indonesia sendiri membuat Indonesia berada pada peringkat keempat di ASEAN (Republika Online, 2013).

Berdasarkan data dari hasil Sensus Penduduk tahun 2010 jumlah penduduk Jawa Barat mencapai sekitar 42 juta jiwa, sehingga menempatkan Jawa Barat dengan jumlah penduduk terbanyak di Indonesia. Jumlah tersebut dari tahun ke tahun menunjukkan 
kenaikan. Peningkatan jumlah penduduk tersebut dibarengi dengan meningkatnya penduduk usia produktif (usia 15 - 65 tahun). Penduduk usia produktif terbagi kedalam angkatan kerja dan bukan angkatan kerja. Berdasarkan data survai ketenagakerjaan Nasional tahun 2012 di Jawa Barat ada 49,45 $\%$ dari total angkatan kerja berpendidikan Sekolah Dasar (SD), dan hanya sedikit seklai yang berpendidikan Perguruan Tinggi. Rendahnya kualitas angkatan kerja akan sulit bersaing dipasaran kerja, selain itu, tenaga kerja tersebut tidak memiliki daya tawar yang tinggi, pada ahirnya kelompok ini menjadi penganggur atau bekerja dengan upah yang sangat rendah, dan biasanya masuk ke sektor informal. Pengangguran memang masih menjadi masalah dibidang ketenagakerjaan. Secara umum permasalahan ketenagakerjaan di Indonesia termasuk Jawa Barat disebabkan tiga hal, yakni kelebihan proporsi tenaga kerja yang tidak trampil, tenaga kerja juga belum siap dengan tuntutan industry, dan bekerja di tempat yang tidak sesusai dengan ketrampilannya.

Pemberlakukan MEA saat ini, telah masuk tenaga asing ke Indonesia termasuk Jawa Barat, tenaga asing tersebut dianggap oleh pengusaha lebih memiliki keahlian atau ketrampilan dan etos kerja yang baik dibanding dengan tenaga kerja lokal. Hal ini dapat memicu konflik.

Tulisan ini membahas tentang gambaran ketenagakerjaan jawa Barat dan kaitannya dengan MEA. Data yang digunakan untuk keperluan bahasan tulisan ini berasal dari data hasil publikasi Biro Pusat Statistik.

\section{PEMBAHASAN}

Berdasarkan data dari hasil Survai Ketenagakerjaan nasional, jumlah penduduk usia kerja di jawa Barat telah mengalami peningkatan yang cukup tinggi, tahun 2013 jumlah penduduk usia kerja 32,8 juta meningkat menjadi 34,1 juta pada tahun 2014. Peningkatan cukup besar. Tabel di bawah memperlihatkan gambaran penduduk usia kerja tahun 2013-2015 didasarkan pada angkatan kerja dan bukan angkatan kerja.
Selama periode 2013-2015 jumlahnya fluktuatif, periode 2013-2014 ada peningkatan, dan pada 2014-2015 mengalami penurunan sekitar 1 juta orang.

Angkatan kerja terdiri dari yang bekerja dan penganggur, bila mencermati angka-angka pada tabel di bawah, ternyata jumlah yang bekerja lebih banyak dibandingkan dengan yang menganggur.Artinya angkatan kerja di Jawa Barat umumnya bekerja, namun demikian mereka yang berstatus menganggur juga harus menjadi perhatian pemerintah, swasta dan masyarakat, karena jika dibiarkan akan memicu terjadinya masalah sosial, sehingga akan menggagu keharmonian kehidupan baik dalam keluarga maupun masyarakat. Sebenarnya masalah ketenagakerjaan yang paling menonjol sampai saat ini adalah pengangguran.secara sederhana penganggurandisebabkanoleh dua hal yaitu banyaknya tenaga kerja dan atau sempitnya kesempatan kerja.

Peningkatan jumlah penduduk usia kerja seharusnya dihadapi dengan penciptaan kesempatan kerja yang memadai. Jika pasar kerja tidak siap untuk menampung mereka, maka terjadilah peningkatan pengangguran secara terus menerus ( Adioetomo; 2005). Kesempatan atau tingkat penyerapan tenaga kerja dalam kegiatan ekonomi di Provinsi Jawa Barat sebenar sudah dapat dikatakan cukup baik, hal ini terbukti dengan data pada tahun 2013-2015 jumlah penganggur yang kurang dari 2 juta jiwa dari seluruh jumlah angkatan kerja. Berdasarkan data dari Sakernas tahun 2015, di Jawa Barat selama kurun waktu 20132015 menunjukkan angka yang fluktuasi (lihat tabel di bawah).

Kelompok yang bukan angkatan kerja, yaitu golongan penduduk berusia kerja yang tidak bekerja, tidak mempunyai pekerjaan dan tidak sedang mencari pekerjaan, serta yang menerima pendapatan tetapi bukan suatu imbalan langsung dari proses produksi. Contoh dari bukan angkatan kerja di sini adalah pelajar atau mahasiswa, ibu rumah tangga. 
Tabel 1.

Penduduk Provinsi Jawa Barat Usia 15 Tahun ke Atas Menurut Kegiatan, Agustus 2013-Agustus 2015

\begin{tabular}{|c|c|c|c|}
\hline \multicolumn{4}{|c|}{$\begin{array}{l}\text { Penduduk Provinsi Jawa Barat Usia } 15 \text { Tahun ke } \\
\text { Atas Menurut Kegiatan, Agustus 2013-Agustus } 2015\end{array}$} \\
\hline Kegiatan & 2013 & 2014 & 2015 \\
\hline $\begin{array}{l}\text { Penduduk } 15 \\
\text { Tahun ke Atas }\end{array}$ & 32.825 .037 & 33.465 .346 & 34.117 .483 \\
\hline $\begin{array}{l}\text { Angkatan } \\
\text { Kerja: }\end{array}$ & 20.620 .610 & 21.006 .139 & 20.586 .356 \\
\hline 1. Bekerja & 18.731 .943 & 19.230 .943 & 18.791 .482 \\
\hline 2. Penganggur & 1.888 .667 & 1.775 .196 & 1.794 .874 \\
\hline $\begin{array}{l}\text { Bukan } \\
\text { angkatan kerja }\end{array}$ & 12.204 .427 & 12.459 .207 & 13.531 .127 \\
\hline
\end{tabular}

Tenaga kerja yang bekerja sebagian besar bekerja di sektor informal (50,39\%), dan hanya 49,61\% yang bekerja di sektor formal contohnya di lembaga pemerintahan, swasta. Menurut Bellante, Don dan Mark Jackson. (2000) para pekerja yang menciptakan sendiri lapangan kerjanya di sektor informal baisanya tidak memiliki pendidikan formal. Biasanya mereka tidak mempunyai keterampilan khusus dan sangat kekurangan modal kerja. Oleh karena itu, produktifitas dan pendapatan mereka cenderung lebih rendah dibandingkan dengan mereka yang berkegiatan di sektor formal

Berdasarkan data yang berasal dari Survey Ketenagakerjaan Nasional tahun 2015, tenaga kerja yang bekerja sebagian besar terserap sektor perdagangan, rumah makan dan sebagainya, kemudian di sektor industri, pertanian perkebunan dan sektor jasa.

Penyerapan terbesar tenaga kerja di Provinsi Jawa Barat pada bulan Agustus 2015

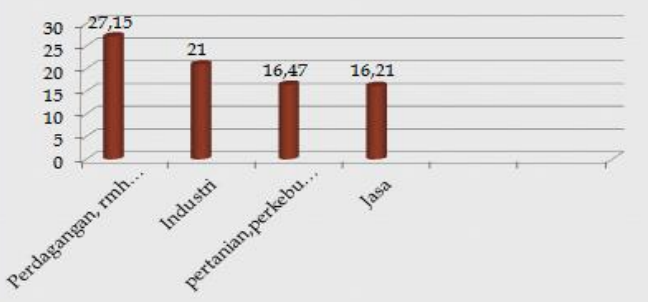

Sumber : BPS,Sakernas 2015.
Banyaknya tenaga kerja yang bekerja di sektor informal terkadang tidak ada kebijakan yang melindungi mereka dari terjadinya kecelakaan di tempat kerja, pengupahan yang kadangkala tidak mengikuti aturan pemerintah. Apabila terjadi kecelakaan saat bekerja yang bersangkutan tidak mendapat perlindungan dari pemerintah, namun sejak tahun 2014 dimana pemerintah mengeluarkan kebijakan tentang perlindungan sosial bagi tenaga kerja baik yang bekerja di sektor formal maupun informal yaitu BPJS Ketenagakerjaan. Hal ini bertujuan untuk melindungi seluruh tenaga kerja.

Kondisi angkatan kerja dilihat dari pendidikan yang ditamatkan, tampak yang bekerja didominasi pendidikan Sekolah Dasar (SD) dan Sekolah Manengah Pertama (SMP), dan hanya sedikit sekali yang berlatar pendidikan Diploma (lihat tabel di bawah ini). Dengan kondisi seperti ini tentu tenaga kerja akan sulit bersaing dengan tenaga kerja yang memiliki latar belakang pendidikan tinggi, padahal pendidikan merupakan unsur yang penting dalam upaya meningkatkan kualitas tenaga kerja agar mampu bersaing di pasaran Asean maupun Global. Berbagai upaya yang telah dilakukan oleh pemerintah dalam upaya meningkatkan pendidikan penduduk, diantaranya dengan kebijakan Wajib Belajar Pendidikan Dasar yang semula hanya 6 tahun kini ditingkatkan menjadi Wajar dikdas 9 tahun (sampai SMP/SLTP). Program tersebut berdampak pada sebagian besar penduduk yang bekerja latar belakang pendidikannya masih rendah (SD dan SMP).

Teori Human Capital menerangkan bahwa pendidikan memiliki pengaruh terhadap pertumbuhan ekonomi karena pendidikan berperan di dalam meningkatkan produktivitas kerja. Teori ini merasa yakin bahwa pertumbuhan suatu masyarakat harus dimulai dari prodiktivitas individu. Jika setiap individu memiliki penghasilan yang tinggi karena pendidikannya juga tinggi. Teori Human Capital ini menganggap bahwa pendidikan formal sebagai suatu investasi, baik bagi individu maupun bagi masyarakat. Selain itu, teori kredensialisme, mengungkapkan bahwa 
pendidikan formal hanya dianggap sebagai alat untuk mempertahankan status quo dari para pemenang status sosial yang lebih tinggi.Menurut teori ini perolehan pendidikan formal tidak lebih dari suatu lambang status (misalnya melalui perolehan "ijazah" bukan karena produktivitas) yang mempengaruhi tingginya penghasilan (Sayuti Hasibuan, 1987).

Gambaran serupa juga dijumpai pada pengangguran, yang didominasi berlatar belakang pendidikan SD dan SMP.Ada hal yang menarik dari tabel di bawah ini, ternyata penganggur yang berlatar belakang Diploma dan Perguruan Tinggi persentasenya cukup lumayan besar, inilah yang sering disebut sebagai penganggur terdidik. Pengangguran terdidik perlu dibahas lebih lanjut karena mereka ini sebenarnya memiliki modal awal, dalam hal ini pendidikan mereka yang cukup untuk mendapatkan keperjaan. Relatif tingginya angka pengangguran terdidik dikarenakan, pada umumnya dalam hal pekerjaan mereka yang berpendidikan tinggi lebih selektif dalam memilih jenis pekerjaan dan upah yang sesuai dengan tingkat pendidikannya (Adioetomo dkk; 2003). Menurut Hasbullah (2012), untuk sebagian golongan masyarakat terdidik di Indonesia, dinamika pertumbuhanekonomi akan sangat berpengaruh terhadap keputusan mereka untuk bekerja atau menunggu pekerjaan yang cocok.

\begin{tabular}{|c|c|c|c|}
\hline \multicolumn{4}{|c|}{$\begin{array}{c}\text { Tabel } 2 \\
\text { Persentase Yang Bekerja dan Pengangguran } \\
\text { Menurut Pendidikan.Februari } 2015 \\
\text { COB }\end{array}$} \\
\hline Pendidikan & Bekerja & pengangguran & \multirow{2}{*}{\begin{tabular}{|l|} 
Total \\
44,73
\end{tabular}} \\
\hline$<=\mathrm{SD}$ & 45,74 & 33,76 & \\
\hline SLTP & 17,68 & 23,27 & 18,15 \\
\hline SMA Umum & 15,51 & 22,06 & 16,06 \\
\hline SMA kejuruan & 10,28 & $(14,81$ & 10,66 \\
\hline Diploma & 2,84 & 1,80 & 2,76 \\
\hline Universitas & 7,96 & 4,29 & 7,65 \\
\hline Tota1 & 100 & 100 & 100 \\
\hline \multicolumn{4}{|c|}{ Sumber: Sakernas 201} \\
\hline
\end{tabular}

Melihan kondisi ketenagakerjaan tersebut, tampak harus berlari cepat untuk mengejar ketertinggalan ini dengan pemerataan pembangunan ekonomi dan peningkatan kualitas Sumber Daya Manusia serta meningkatkan taraf hidupnya.Ahir-ahir ini banyak tenaga asing yang bekerja di Indonesia, sehingga menjadi sorotan dari berbagai pihak karena beberapa industri telah mempekerjakan tenaga yang berasal dari negara Cina. Hal itu sah-sah saja, ini dampak adanya MEA. Untuk menghadapi MEA Jawa Barat harus mempersiapkan sumber daya manusia yang terampil,cerdas dan kompotitif.

Adanya MEA tentu memiliki dampak baik yang positif maupun negatif. Dampak porsitif yang timbul dari adanya MEA, diantaranya tenaga terampil Indonesia dan Jawa Barat akan lebih terserap di luar negri,adanya pasar bebas Asean ada kemungkinan harga-harga lebih murah karena ketersediaan barang lebih banyak,sektor wirausaha terbuka lebar,bahan baku industri akan lebih beragam baik dari sisi harga maupun jenis barangnya.

Dampak denatif yang dapat timbul diantara,banyak produk luar yang masuk ke Indonesia dengan harga yang lebih murah, jika keadaan ini dibiarkan akan mematikan produkproduk lokal, karena masyarakat cenderung membeli produk-produk luar dengan alasan kualitas lebih baik dengan harga yang lebih murah dibandingkan dengan produk lokal. Ahirnya banyak pelaku usaha di dalam negeri yang tutup, jika sudah terjadi seperti ini maka jumlah pengangguran akan bertambah. Indonesia termasuk Jawa Barat akan kebanjiran barang-barang selundupan. Tidak menutup kemungkinan akan ada pendatang gelap, keadaan ini sebenarnya bisa diatasi bila saja sistem administrasi kependudukan dijalankan dengan benar, karena administrasi kependuduk bertujuan agar tercipta tertib administrasi, sehingga tidak ada lagi pendatang gelap.

Kehadiran idak perlu dilihat sebagai ancaman, tetapi bisa dijadikan sebagai peluang untuk dimanfaatkan semaksimal mungkin. Peluang yang ada diantaranya terbuka luas perdagangan dan jasa online, saat ini sudah mulai diberlakukan jasa online terutama pada jasa transportasi. Sektor pariwisata akan terbuka sehingga dapat menarik wisatawan 
lokal maupun mancanegara yang pada ahirnya dapat menyumbang devisa.

\section{PENUTUP}

Kualitas tenaga kerja Jawa Barat masih rendah, hal ini didasarkan pada mayoritas berpendidikan SD dan SMP, sehingga mereka akan sulit untuk masuk dan bersaing dengan tenaga kerja yang berasal dari luar Indonesia yang cenderung memiliki ketrampilan dan keahlian yang dibutuhkan oleh industri atau oleh para pelaku bisnis. Dengan demikian lapangan kerja yang dimasuki mayoritas di sektor informal, mereka ini tidak mendapatkan perlindungan sosial dari pemerintah. Untuk menghadapi MEA, agar tenaga kerja memiliki kualitas dan ketrampilan yang memadai bagi dunia usaha, maka perlu kerja keras untuk meraih ketertinggalan. Dengan demikian tenaga kerja Jawa Barat memiliki ketrampilan dan kualitas yang tinggi.

\section{DAFTAR PUSTAKA}

Adioetomo, Sri Moertiningsih Setyo. 2005. "Bonus Demografi". Fak Ekonomi UI. Jakarta

Adioetomo, Sri Moertiningsih \& Nur hadi W.2003. "Isu dan Prospek Ketenagakerjaan dan Mobilitas Penduduk di Indonesia". Warta demografi tahun ke 33 No 3. LD-UI. Depok

Biro Pusat Statistik. 2015. "Sakernas tahun 2013, 2014 dan 2015". Jakarta.

Hasibuan, Sayuti. 1987." Changing Manpower Requirements in The Face of Non-Oil Growth, Labor Force Growth and Fast Tehnological Change". Bappenas. Jakarta

Bellante, Don dan Mark Jackson. (2000). "Ekonomi Ketenagakerjaan" (Wimandjaja K. Liotohe, MPE dan M. Yasin, SE, M.Sc. Terjemahan). Jakarta: FE UI. Buku asli diterbitkan tahun 1983. 